\title{
Regimen Used to Treat Acute Myeloid Leukemia
}

National Cancer Institute

\section{Source}

National Cancer Institute. Regimen Used to Treat Acute Myeloid Leukemia. NCI

Thesaurus. Code C63589.

Any regimen that can be used for the treatment of acute myeloid leukemia (AML). 